\title{
LOS PERGAMINOS DE AURELIANO BABILONIA
}

\author{
POR \\ MICHAEL PALENCIA-ROTH \\ University of Illinois
}

«Toda buena novela es una adivinanza del mundo» ${ }^{1}$. Esta frase, pronunciada por García Márquez con respecto a Cien años de soledad, señala un sendero que ha de tomar la crítica. Naturalmente, no nos presenta una interpretación definitiva. Sin embargo, como la búsqueda de las mejores interpretaciones es el raison d'être del crítico, y como en este caso la sugerencia de García Márquez nos parece razonable, proponemos meditar las consecuencias de esta definición sobre la novela.

"Adivinanza» tiene dos acepciones principales. Una, de «adivinación», con el significado de predecir el futuro, lo oculto o lo desconocido; de resolver un enigma. La otra, la de «acertijo»: presentar un problema o enigma que se propone como pasatiempo. En ambos casos, algo oculto o desconocido ha de ser traído a la luz, ha de ser «conocido», descifrado. E1 acto de descrifrar presupone la existencia de la cifra; y ésta se descifra por medio de la clave. Y la clave de la cifra de Cien años de soledad ha de buscarse en los pergaminos de Aureliano Babilonia o, mejor dicho, en la metáfora de éstos. Críticos como Rodríguez Monegal -el mejor sobre los enigmas de la novela- han contribuido a nuestro análisis, y no intentamos entrar en polémica con él o con ellos. Reconocemos la deuda. Ahora bien: la investigación que sigue nos lle-

${ }^{1}$ Armando Durán, «Conversaciones con Gabriel García Márquez», Revista Nacional de Cultura (Caracas), 29, núm. 185 (julio-agosto-septiembre de 1968), p. 28. Véase también las siguientes palabras de García Márquez en una entrevista con Plineo Apuleyo Mendoza (1972): «Yo creo que toda novela es una representación cifrada de la realidad - o como he dicho alguna vez: una adivinanza del mundo--, pero esta representación, a cualquier profundidad y a cualquier latitud, tiene una naturaleza propia, con sus leyes precisas e inviolables», en Alfonso Rentería Mantilla (ed.), García Márquez habla de García Márquez (Bogotá: Rentería Editores, Ltda., 1979), p. 87. 
vará no sólo a una consideración del Aleph de Borges (la comparación esencial de Rodríguez Monegal), sino también a la relación entre la profecía y el apocalipsis; a los temas de la circularidad, la eternidad y el amor; a la idea del «espejo hablado» (que da título a un libro sobre la novela); al papel que desempeña Melquíades en la obra y, finalmente, a la relación de Cien años de soledad con dos autores importantes para la interpretación de García Márquez: Cervantes y Sófocles.

El enigma de Cien años de soledad no está en sus temas (por ejemplo, la soledad o el incesto), por interesantes que sean, sino en su forma, y ésta, como han afirmado varios críticos, es circular ${ }^{2}$. En la «última madrugada de Mancondo ${ }^{3}$, el incesto de Amaranta Ursula y Aureliano Babilonia hace pensar en ese primer incesto, el de José Arcadio Buendía y Ursula Iguarán de Buendía, y también en ese otro Macondo que existió unos cien años antes (tal vez más), cuando «el mundo era tan reciente, que muchas cosas carecían de nombre» (p. 9). Al final de la novela todo parece regresar, aunque algo trastornado por el transcurso aparente del tiempo, al principio. En el círculo, según unos de los aforismos de Heráclito, el comienzo y el fin son idénticos. Sin embargo, el principio y el fin de Cien años de soledad no son idénticos, sino homólogos, y esto debido a que, como en los grandes mitos del mundo, la novela relata el comienzo y el fin de todas las cosas ${ }^{4}$.

Quizá otro novelista se contentaría en dejar que el ciclo se completase sin complicaciones: que Macondo y sus Buendía se hundiesen silenciosamente en esa naturaleza de donde salieron. Podríamos entonces concluir de ellos únicamente lo que el cónsul —en La vorágine de José Eustacio Rivera- dice de Arturo Cova y sus compañeros: «los devoró la selva». Pero García Márquez no es «otro» novelista, y no se puede escribir hacia 1965 como se escribía en la década de 1920. A diferencia de $L a$ vo-

${ }^{2}$ La tesis de la importancia de la circularidad en García Márquez es central en el argumento de Mario Vargas Llosa, García Márquez: historia de un deicidio (Caracas: Monte Avila Editores, 1971). Véase especialmente el capitulo que se titula «El punto de vista temporal: el tiempo circular, episodios que se muerden la cola» (pp. 545-565). Otros críticos también han señalado la importancia de la circularidad: por ejemplo, Ricardo Gullón, Carmen Arnau, Josefina Ludmer, Suzanne Jill Levine, Julio Ortega.

${ }^{3}$ Gabriel García Márquez, Cien años de soledad (Buenos Aires: Editorial Sudamericana, 1967), p. 348. En adelante incluimos las citas en nuestro texto.

${ }^{4}$ La homología de los relatos del comienzo del mundo (la cosmogonía) y esos del fin (la escatología) es idea fundamental de Mircea Eliade, de muchos otros críticos de la mitología y de muchos antropólogos. Véase, por ejemplo, Mircea Eliade, The Myth of the Eternal Return (Princeton: Princeton University Press, 1977). 
rágine, que es una obra esencialmente lineal, Cien años de soledad abunda en "complicaciones circulares», en técnicas tales como la repetición de los nombres; en problemas como la relación entre el individuo y su destino, como la función de Melquíades en la novela, o inclusive como la metáfora de los pergaminos.

Para entender dicha metáfora - y todo lo demás - naturalmente hay que descifrar los pergaminos. Aquí ayuda la venganza del tabú del incesto, es decir, el hijo nacido con cola de cerdo ${ }^{5}$. Después de la muerte de Amaranta Ursula, Aureliano Babilonia, quien había pasado la noche emborrachándose y quejándose de su mala fortuna, se recuerda de repente de su niño. Buscándolo por toda la casa, lo encuentra al fin convertido en un pellejo hinchado y reseco, arrastrado por las hormigas por el sendero de piedras del jardín:

Aureliano no pudo moverse. No porque lo hubiera paralizado el estupor, sino porque en aquel instante prodigioso se le revelaron las claves definitivas de Melquíades, y vio el epígrafe de los pergaminos perfectamente ordenado en el tiempo y el espacio de los hombres: $E l$ primero de la estirpe está amarrado a un árbol y al último se lo están comiendo las hormigas (p. 349).

La clave de los pergaminos es simultáneamente la clave de su destino (p. 349) y de la novela: la adivinanza del mundo.

Los pergaminos contienen la historia de los Buendía, «escrita por Melquíades hasta en sus detalles más triviales, con cien años de anticipación» (p. 349). Con la clave a mano, Aureliano Babilonia puede leerlos «sin la menor dificultad, como.si hubieran estado escritos en caste1lano» (p. 349), aunque realmente estaban escritos en sánscrito. Además, Melquíades había cifrado los versos pares e impares con dos claves distintas y «no había ordenado los hechos en el tiempo convencional de los hombres, sino que concentró un siglo de episodios cotidianos, de modo que todos coexistieran en un instante» (p. 350), esto es, en el tiempo presente (gramatical) del epígrafe de los pergaminos. Al igual que Joyce en Finnegans Wake, novela que se desarrolla en un solo momento durante el sueño de HCE, Melquíades (o García Márquez) ha escrito un libro donde todo existe simultáneamente. El filósofo inglés llamaría a esta simultaneidad total la identidad del hic-stans y del nunc-stans (del

${ }^{5}$ Véase Sigmund Freud, Totem und Tabu, obra que se escribe en 1912-1913. Desarrollamos la idea del tabú del incesto y su función tanto estructural como temática en otro ensayo. Véase «La imagen del Uroboros: el incesto en Cien años le soledad", Cuadernos Americanos, CCXXVII, núm. 4 (1981), 67-82. 
aquí y del ahora) ${ }^{\sigma}$; es, por supuesto, una idea religiosa. El único tiempo cronológico («el tiempo convencional de los hombres» o «la historia») es ese que experimentamos nosotros al leer la novela o los Buendía al vivir sus vidas. Por necesidad, el primero es un tiempo lineal, pero el tiempo de la novela misma, dado que cada momento es idéntico con cada otro, es el de la eternidad ${ }^{7}$.

A lo largo de la novela, García Márquez ha ido preparando la idea de la eterna coexistencia del tiempo y del espacio. Por ejemplo, esta idea precipita la locura de José Arcadio Buendía. Una mañana, él entra al taller de su hijo Aureliano y le pregunta, «¿Qué día es hoy» (p. 73). Al oír la respuesta ( «hoy es martes»), José Arcadio Buendía le contesta: «eso mismo pensaba yo. Pero de pronto me he dado cuenta que sigue siendo lunes, como ayer» (p. 73). Como prueba, señala el espacio circundante: «mira el cielo, mira las paredes, mira las begonias. También hoy es lunes» (p. 73). El día próximo (miércoles), el aire y el sol le siguen indicando «lunes». $Y$ el jueves, el fundador de Macondo, sollozando que «la máquina del tiempo se ha descompuesto» (p. 73), se pone a examinar las cosas por seis horas, tratando de descubrir en ellas el transcurso del tiempo. El viernes se enloquece por completo, y se necesitan veinte hombres para arrastrarlo al castaño y amarrarlo. Allí lo dejan, «ladrando en lengua extraña y echando espumarajos verdes por la boca» (p. 74). Ursula y Amaranta, al regresar a la casa, lo encuentran en un lunes eterno, «en un estado de inocencia total» (p. 74). Preso e inmóvil bajo el castaño, José Arcadio Buendía se transforma para siempre en una especie de santo loco, en una metáfora viviente en el espacio atemporal y en el tiempo ahistórico.

${ }^{6}$ «Pero quieren enseñarnos que la eternidad es la detención del tiempo presente, un nunc-stans, como lo llaman los escolásticos; ni ellos ni nadie más entienden eso, ni entenderían un hic-stans como la infinidad del espacio.» Thomas Hobbes, Leviathan, editado por Michael Oakeshott de la versión de 1651 (Oxford: Basil Blackwell, 1957), p. 443. Todas las traducciones del inglés en este artículo son mías.

${ }^{7}$ Josefina Ludmer, en 'Cien años de soledad': una interpretación (Buenos Aires: Tiempo Contemporáneo, 1972), considera en su último capítulo (pp. 215-222) lo que ella denomina «cierre de la ficción». Según Ludmer, el fin de la novela demuestra la coexistencia de la 'profecía' (el presente volteado hacia el futuro) y de la 'narración' (el presente volteado hacia el pasado), la coexistencia de los tiempos futuro, presente y pasado «produciendo un precipitado total» (p. 217). Esto resulta, según ella, en «la aniquilación del tiempo» (p. 217). Ahora bien: por razones que indicamos en nuestro texto, la tradición en la cual se fundamenta Cien años de soledad no es la profética, sino la apocalíptica. También, la coexistencia de todos los tiempos resulta, no en su "aniquilación», sino en 'su elevación al tiempo eterno, en su apoteosis. 
Las varias descripciones del cuarto de Melquíades también anticipan la metáfora de la eternidad expuesta al final de la novela. Por ejemplo, cuando el adolescente Aureliano Segundo abre las ventanas del «cuarto clausurado» de Melquíades, que nadie había abierto desde que sacaron el cadáver de éste, se indica:

Entró una luz familiar, que parecía acostumbrada a iluminar el cuarto todos los días, y no había el menor rastro de polvo o telaraña, sino que todo estaba barrido y limpio, mejor barrido y más limpio que el día del entierro, y la tinta no se había secado en el tintero ni el óxido había alterado el brillo de los metales, ni se había extinguido el rescoldo del altanor donde José Arcadio Buendía vaporizó el mercurio. En los anaqueles estaban los libros empastados en una materia acartonada y pálida como la piel humana curtida, y estaban los manuscritos intactos. A pesar del encierro de muchos años, el aire parecía más puro que en el resto de la casa (pp. 160-161).

Es aquí en este cuarto eterno ${ }^{8}$, que parece existir al otro lado del tiempo y del espacio, donde Aureliano Babilonia descrifra los pergaminos. Al leerlos, Aureliano Babilonia empieza a darse cuenta de que el momento eterno de los pergaminos es simultáneamente el momento en que él vive y en que los descifra. Su acto de leer es eterno:

Empezó a descifrar el instante que estaba viviendo, descifrándolo a medida que lo vivía, profetizándose a sí mismo en el acto de descifrar la última página de los pergaminos, como si se estuviera viendo en un espejo hablado (p. 350).

La imagen del espejo hablado confirma lo que ya sabemos: Cien años de soledad y los pergaminos de Melquíades son, en todo detalle, el mismo libro. De la misma manera, el lenguaje de los pergaminos (sánscrito) es a la vez castellano; y el castellano, sánscrito. Los pergaminos están escritos en nuestra propia lengua materna. Como ésta simultánea-

${ }^{8}$ Admitimos, sin querer insistir en ello, la inconsistencia de García Márquez en sus varias descripciones del cuarto. No sé $-\mathrm{y}$, a la verdad, no me parece importante - si estas inconsistencias fueron intencionales (¿una de las 42 contradicciones en la novela, según el autor?) o no. Cuando se describe el cuarto de Melquíades, éste parece existir, la mayoría de las veces, fuera del tiempo: el aire es fresco y puro; los pergaminos están muy bien conservados. Algunas veces, sin embargo, el cuarto, igual a cualquier otra parte de la casa, cambia con el tiempo. Tal cambio ha ocurrido cuando Aureliano Babilonia entra en el cuarto por última vez. El encuentra los pergaminos intactos «entre las plantas prehistóricas y los charcos humeantes y los insectos luminosos que había desterrado del cuarto todo vestigio del paso de los hombres por la tierra» (p. 349). 
mente es sánscrito (símbolo del mundo prehistórico) y castellano (símbolo del moderno), los pergaminos incluyen toda la prehistoria y la historia, coexistiendo en un solo momento, que es el presente, y éste es eterno.

Analicemos el significado de esta imagen cósmica (pergaminos $=$ Cien años de soledad $=$ el mundo $=$ la prehistoria $=1$ la historia $=$ el momento presente $=$ la eternidad). Invoquemos por el momento la ayuda de dos guías expertos en asuntos latinoamericanos: a Emir Rodríguez Monegal y a Jorge Luis Borges. Rodríguez Monegal ha llamado los pergaminos de Melquíades «an Aleph image of the world» (una imagen Aleph del mundo) ${ }^{9}$. Rodríguez Monegal ha tomado el vocablo Aleph, que es la primera letra del alfabeto hebreo, del cuento de Borges del mismo nombre. Posiblemente hay influencia, en este caso, de Borges en García Márquez. Se dice que el colombiano ha leído la obra entera del argentino. Dejemos la cuestión de influencia a un lado porque, de una manera o de otra, la didáctica lucidez de «El Aleph» contribuye mucho a una explicación de Cien años de soledad.

El cuento trata de un narrador, llamado Borges, quien establece amistad con el poeta Carlos Argentino Daneri. Argentino, después de algún tiempo de amistad, le revela a Borges que en el ángulo del sótano de cierta casa hay un Aleph. Este, explica Argentino, es «uno de los puntos del espacio que contienen todos los puntos» (p. 209) ${ }^{10}$. Al ver que Borges-narrador no entiende, Argentino le explica un poco más: el Aleph es «el lugar donde están, sin confundirse, todos los lugares del orbe, visto desde todos los ángulos» (p. 209). Más tarde amplía su definición original: el Aleph es «el microcosmo de alquimistas y cabalistas... el multum in parvo» (p. 221). Curioso, el narrador se deja encerrar en dicho sótano. Después de unos momentos de duda y de terror (piensa que Argentino está loco y que quiere matarlo), ve de repente el Aleph. Despreciando su habilidad de describir lo indescriptible, escribe:

En ese instante gigantesco ${ }^{11}$ he visto millones de actos deleitables o atroces; ninguno me asombró como el hecho de que todos ocuparan

9. Véase Emir Rodríguez Monegal, «One Hundred Years of Solitude: The Last Three Pages», Books Abroad, 47 (1973), p. 487. Nuestra interpretación coincide en ciertos aspectos con la suya, pero utilizamos la obra de Borges para subrayar más las diferencias que las semejanzas entre Borges y García Márquez.

10. Jorge Luis Borges, El Aleph: relatos (Barcelona: Editorial Planeta, 1969), p. 209. Incluimos las citas en nuestro texto.

${ }^{11}$ En Cien años de soledad la epifanía de Aureliano Babilonia se describe como «aquel instante prodigioso» (p. 349). 
el mismo punto, sin superposición y sin transparencia. Lo que vieron mis ojos fue simultáneo: lo que transcribiré, sucesivo, porque el lenguaje lo es. Algo, sin embargo, recogeré.

En la parte inferior del escalón, hacia la derecha, vi una pequeña esfera tornasolada, de casi intolerable fulgor ${ }^{12}$. Al principio la creí giratoria; luego comprendí que ese movimiento era una ilusión ${ }^{13}$ producida por los vertiginosos espectáculos que encerraba. El diámetro del Aleph sería de dos o tres centímetros, pero el espacio cósmico que estaba ahí, sin disminución de tamaño. Cada cosa (la luna del espejo, digamos) ${ }^{14}$ era infinitas cosas, porque yo claramente la veía desde todos los puntos del universo. Vi el populoso mar, vi el alba y la tarde, vi las muchedumbres de América, vi una plateada telaraña en el centro de una negra pirámide, vi un laberinto roto (era Londres)... vi el Aleph, desde todos los puntos, vi en el Aleph la tierra, y en la tierra otra vez el Aleph y en el Aleph la tierra ${ }^{15}$, vi mi cara y mis vísceras, vi tu cara y sentí vértigo y lloré, porque mis ojos habían visto ese objeto secreto y conjetural, cuyo nombre usurpan los hombres, pero que ningún hombre ha mirado; el inconcebible universo ${ }^{16}$ (pp. 212-214).

Este lúcido pasaje se compara fácilmente - aunque siento no tener el espacio para llevar a cabo una comparación a fondo- a Cien años de soledad. $\mathrm{El}$ «instante gigantesco» del Aleph, cuya descripción cubre dos páginas de Borges, se extiende, en la novela de García Márquez, a unas trescientas cincuenta páginas. Borges relata la visión como un momento $E N$ la narración, pero para García Márquez la visión $E S$ la narración. Borges describe el Aleph; García Márquez lo crea. Borges lamenta que la simultaneidad total de su visión no puede reducirse al lenguaje, que es parcial y lineal; García Márquez, sin quejarse, simplemente escribe

12 Northrop Frye denomina esta visión «el punto de la epifanía»; ocurre, según él, la mayoría de las veces en lugares como la cumbre de una montaña, torres, faros, escaleras o escalones. Véase The Anatomy of Criticism (New York: Atheneum, 1967), p. 201.

${ }^{13}$ Lo mismo podría decirse de «la rueda giratoria» (p. 334) en Cien años de soledad.

${ }^{14}$ Esta imagen recuerda la de la luna y el espejo en el primer párrafo de $L a$ hojarasca.

${ }^{15}$ He aquí «el espejo hablado» de la p. 350 de la novela. Esta metáfora la utiliza Suzanne Jill Levine como título de su libro: El espejo hablado: un estudio de 'Cien años de soledad' (Caracas: Monte Avila Editores, 1975). Véase también el artículo de Aleyda Roldán de Nicolta, «Cien años de soledad: una novela construida sobre espejos», Explicación de Textos Literarios, 6, anejo 1 (1976), pp. 239-258.

${ }^{16}$ Aunque José Arcadio Buendía tiene una idea intuitiva de lo que es uel inconcebible universo», Aureliano Babilonia es el único Buendía que verdaderamente lo ha vistó. 
Cien años de soledad. No hay mejor ejemplo, me parece, que destaque así tan claramente las diferencias de talento e inclinación temperamental entre el argentino y el colombiano.

Ahora bien: ¿cómo se puede captar tal visión entre los forros de un libro? ¿No será imposible? Teóricamente, sí; en la práctica, no. Pues García Márquez lo ha hecho. Apoyándonos primero en las palabras del crítico canadiense Northrop Frye, la técnica de tal visión describe «un universo compuesto totalmente de metáforas, donde cada cosa es, potencialmente, idéntica a cada otra, como si existiese todo dentro de un solo cuerpo infinito» ${ }^{17}$. Según Frye, tal visión es apocalíptica. Al unir la idea del apocalipsis con la de la «imagen cósmica», se descifran sin gran dificultad casi todos los enigmas de Cien años de soledad.

Dicho término proviene de la teoría del crítico francés Gastón Bachelard ${ }^{18}$. Una imagen cósmica, afirma él, capta en la mente un mundo entero $o$ un inmenso universo. Tales imágenes o visiones, aunque generalmente raras, se encuentran a menudo en los sueños de la niñez y en las concepciones míticas del hombre primitivo ${ }^{19}$. Opina Bachelard que los adultos, al soñar en imágenes cósmicas, desean recobrar y revivir la cosmicidad de la niñez. En las grandes soledades de la infancia -y nótese la importancia del tema para García Márquez- figura con frecuencia la cosmicidad onírica, imaginativa y creadora. En Cien años de soledad, la técnica de la «cosmicidad» de la imagen se une a la idea religiosa del apocalipsis, utilizada ésta ya por García Márquez en «Un día después del sábado» y en «Los funerales de la Mamá Grande».

Tradicionalmente, la literatura apocalíptica es secreta; está escrita en libros «ocultos», que se revelarán a «los hombres justos» o «rectos» al fin del mundo. Nadie en la familia Buendía, notémoslo, puede descifrar los pergaminos antes del tiempo designado por Melquíades ${ }^{20}$. Aure-

${ }^{17}$ Frye, The Anatomy of Criticism, p. 136.

${ }^{18}$ Véase especialmente el libro de Bachelard titulado La poétique de l'espace (Paris: Presses Universitaires de France, 1958).

${ }^{19}$ Se ha notado la importancia que tiene la niñez para García Márquez, quien una vez dijo que después de los ocho años no le habia pasado nada importante, pero que antes había vivido mucho. Véase Miguel Fernández-Braso, La soledad de Gabriel García Márquez: una conversación infinita (Barcelona: Editorial Planeta, 1972), p. 118.

${ }^{20}$ Lo mismo ocurre en Daniel, libro «apocalíptico» del Antiguo Testamento. A Daniel se le ordena cerrar las palabras y sellar el libro hasta «el Tiempo del fin» (Daniel, 12,4). Y cuando Daniel le pregunta a Dios por qué, éste le contesta: «Anda, Daniel, que estas palabras están cerradas y selladas hasta el tiempo del cumplimiento» (Daniel, 12,9). A excepción de un artículo, como el de Lois P. Zamora, "The Myth of Apocalypse and Human Temporality in García Márquez's 
liano Babilonia, quien domina el idioma cabalístico (sánscrito) de los pergaminos y quien es, quizá paradójicamente, el único Buendía «recto» o «justo» (pues es el único que ha engendrado un hijo "por el amor»), sí puede descifrarlos. Además, conforme con las tradiciones apocalípticas, los descifra en la última hora de la existencia de Macondo ${ }^{21}$.

A diferencia de la tradición profética, que es oral, la tradición apocalíptica es escrita; termina siendo literatura ${ }^{22}$. Melquíades, se recordará, se preocupa mucho en escribir sus revelaciones, en hacer literatura. La numerología es también importante en la tradición apocalíptica: los «cien años» del título, y su significado dentro de la novela, confirman la importancia de dicha tradición.

La literatura apocalíptica interpreta la historia desde un punto de vista determinista. Como se explica en Daniel $(11,36)$, lo que se ha precisado ocurrirá. Es solamente al leer los pergaminos cuando Aureliano Babilonia entiende que el ciclo del incesto ha sido predeterminado:

Sólo entonces descubrió que Amaranta Ursula no era su hermana, sino su tía, y que Francis Drake había asaltado a Riohacha solamente para que ellos pudieran buscarse por los laberintos más intrincados de la sangre, hasta engendrar el animal mitológico que había de poner término a la estirpe (p. 350).

«Todo se sabe», había dicho Aureliano Babilonia muchas veces, repitiendo lo que había dicho Melquíades en su tiempo y José Arcadio en el suyo (véase p. 322). Yo diría que sí, que todo se sabe, pero a su tiempo. Sabemos ahora, por ejemplo, que la repetición en la novela sirve como índice del destino, de la predeterminación ${ }^{23}$. El nombre de cual-

Cien años de soledad and El otoño del patriarca", Symposium, 32 (1978), pp. 341355, la mayoría de la crítica, inclusive la mítica, se concentra en otros aspectos míticos de la novela. Por ejemplo, Germán Darío Carrillo, en su artículo «Mito bíblico y experiencia humana en Cien años de soledads, Explicación de Textos Literarios, 6, anejo 1 (1976), pp. 79-100, considera solamente el mito adánico del Paraíso Terrenal y de la caída. No nos dice nada sobre el fin del mito bíblico: el apocalipsis.

${ }^{21}$ La revelación de San Juan sólo ocurre cuando «el tiempo está cerca» (Apocalipsis, 1,3). Además, el apellido de Aureliano Babilonia recuerda, obviamente, la ciudad de Babilonia en el Apocalipsis, la ciudad que se destruye «en una hora» (Apocalipsis, cap. 18). También la confusión de lenguas sugerida por el término «Babel» indica simbólicamente las múltiples lenguas que conlleva la metáfora de los manuscritos de Melquíades.

${ }^{22}$ Véase nuestro comentario en la nota 7.

${ }^{23}$ La predestinación por medio de la repetición del nombre es ejemplo biográfico del «eterno retorno» (véase nota 4). Esta idea se asocia con la de gelebte vita 
quier personaje predetermina su personalidad y la trayectoria de su vida. Como hay solamente dos tipos esenciales de Buendía varones, se repiten constantemente los nombres; esto lo sabía Ursula. Como dijo ella, «mientras los Aureliano eran retraídos, pero de mentalidad lúcida, los José Arcadio eran impulsivos y emprendedores, pero estaban marcados por un signo trágico» (p. 159).

Según la versión apocalíptica de la historia del mundo, todo procede hacia la destrucción inevitable. Esto lo entiende Pilar Ternera como un proceso predeterminado en el mundo de los Buendía, pues ella reconoce, mejor quizá que cualquier otra persona en la novela, «que la historia de la familia era un engranaje de repeticiones irreparables, una rueda giratoria que hubiera seguido dando vueltas hasta la eternidad, de no haber sido por el desgaste progresivo e irremediable del eje» (p. 334). En el mundo de la novela, lo que contribuye muchísimo a ese desgaste del eje son las numerosas plagas (recordemos, también, las plagas del Apocalipsis de San Juan). La primera plaga es la del insomnio y del olvido; la segunda, las guerras civiles que casi destruyen al pueblo; la tercera, la decadencia con la explotación del banano y la predeterminada massacre de tres mil personas frente a la estación del ferrocarril ${ }^{24}$; la cuarta, el diluvio, que dura cuatro años, once meses y dos días; la quinta, la de la selva devoradora al final de la novela; la sexta, ese «huracán bíblico» que convierte a Macondo en «un pavoroso remolino de polvo y escombros» (p. 350). Generalmente, las plagas en el Apocalipsis de San Juan, o destruyen al hombre físicamente, o destruyen la naturaleza: diviesos y llagas, vientos, fuegos, diluvios, pestilencias. Pero una de las plagas que aflige a la Babilonia bíblica es la psicológica: la del llanto. Aficionados por el momento a la numerología, digamos que en Cien

(vida experimentada), concepto básico del mito que se encuentra en la literatura moderna en forma ejemplar en la novela Joseph und seine Brüder (José y sus hermanos) de Thomas Mann. En esa novela hay, en cada generación, un criado llamado Eliezer, cuya personalidad es siempre igual. Mann comenta este fenómeno con su acostumbrada lucidez didáctica.

${ }^{24}$ Este episodio se basa en un hecho histórico. En 1928, una huelga de peones bananeros, en la costa atlántica de Colombia, fue terminada por una massacre frente a la estación del ferrocarril de Ciénaga, un pueblo en la zona bananera. El número de muertos varía, según las simpatías del narrador, de cero a miles. Los datos históricos pueden encontrarse en el siguiente artículo de Lucila I. Mena, «La huelga bananera como expresión de lo 'Real Maravilloso' americano en Cien años de soledad», Bulletin Hispanique, 74 (1972), pp. 379-405; o en muchos libros de la historia de Colombia, por ejemplo, en el de Diego Montaña Cuéllar Colombia: pais formal y pais real (Buenos Aires: Editorial Planeta, 1963), pp. 126-129. Esta huelga - junto con su massacre- es tema de una novela ( $L a$ casa grande, 1967) escrita por un amigo de García Márquez, Alvaro Cepeda Samudio. 
años de soledad debe haber siete plagas en total (el siete es número místico y bíblico) ${ }^{25}$. La séptima sería la plaga de la soledad, que es la única que es mental, pero también la más constante. Pues todo Buendía vive condenado a ella. Semejante al signo de la prostituida Babilonia, en cuya frente se encuentra escrito "Misterio, Babilonia la Grande, la madre de las fornicaciones y de las abominaciones de la tierra» (Apocalipsis, 17,5), todo Buendía lleva el signo de la soledad, o inscrita en la frente (los 17 Aureliano), o llevado como cicatriz en el corazón, o como llaga en el alma. Este signo es índice simultáneamente de la pertenencia a la familia del juicio final y de la condenación ${ }^{26}$.

Circular es la novela: en sus últimos momentos de vida, cada Buendía regresa o a su nacimiento o a un episodio en el pasado remoto. El amor de Amaranta Ursula y de Aureliano Babilonia, que ocurre en un «paraíso» (vocablo que se encuentra varias veces en las páginas finales), repite en cierto sentido la vida de un Macondo primitivo. La ciudad ruidosa de Macondo se torna otra vez en pueblo, en aldea; y la casa en la selva de donde salió. He aquí, pues, el Uroboros, el dragón que se muerde la cola. Analógicamente, el mito apocalíptico es también el mito del Uroboros (el de la circularidad), pues de una destrucción total nace otro mundo nuevo, completándose el círculo e iniciándose otro. En el apocalipsis cristiano, ese mundo nuevo es la Nueva Jerusalén, ciudad de piedra «resplandeciente como cristal», con una plaza de «oro puro como vidrio transparente» (Apocalipsis, 21,11.21). Por esta ciudad corre "un río limpio de agua de vida, resplandeciente como cristal» (Apocalipsis 22,1); las aguas del río que pasa por Macondo son «diáfanas», parecidas a «un torrente de vidrio helado» (p. 28). La Nueva Jerusalén es ciudad de espejos, de cristales; Macondo había de ser —según el sueño profético de José Arcadio Buendía - «una ciudad ruidosa con casas de paredes de espejo» (p. 28). Siendo una especie de Paraíso Terrenal al comienzo de Cien años de soledad, Macondo podría llamarse la Nueva Jerusalén latinoamericana. Pero como se destruye -y en la Biblia tal destrucción es preludio de la Nueva Jerusalén-, podría llamarse al fin una Babilonia

${ }^{25}$ En el Apocalipsis también hay siete plagas: «Y fue el templo lleno de humo por la majestad de Dios, y por su potencia; y ninguno podía entrar en el templo, hasta que fuesen consumadas las siete plagas de los siete ángeles» (Apocálipsis, $15,8)$.

${ }^{26}$ De acuerdo con las teorías de Sigmund Freud en Totem y tabú, podríamos designar tal indicio como un totem, que funciona a la vez como signo de pertenencia a la familia y como prohibición (tabú) absoluta del incesto, prohibición que, como no se obedece, resulta en la destrucción de la familia y del mismo Macondo. Desarrollamos esta idea en otro ensayo. Véase nota 5. 
latinoamericana (he aquí, quizá, el significado del apellido del último Buendía). O podríamos decir con Borges que Macondo es una ciudad Aleph: una ciudad en la cual se reflejan todas las ciudades de la tierra; y ella en todas las ciudades. Todo parece ser un espejo hablado y todo, en esta novela de espejismos, obedece a la ley de la circularidad ${ }^{27}$.

Desde la perspectiva mítica, el tiempo es también cíclico; por lo que García Márquez viene a ser un escritor mítico. Pero al decir esto nos enfrentamos con lo que parece ser una contradicción fundamental en la obra de García Márquez, pues, desde el punto de vista del apocalipsis judeo-cristiano, el tiempo es esencialmente lineal. La historia del hombre, según esta interpretación, transcurre sucesivamente sin constantes repeticiones cíclicas, hasta culminar en la destrucción del mundo, el juicio final y la Nueva Jerusalén. En las últimas palabras de la novela, García Márquez parece aliarse con esta interpretación lineal de la historia del hombre:

Todo escrito [en los pergaminos] era irrepetible desde siempre y para siempre, porque las estirpes condenadas a cien años de soledad no tenían una segunda oportunidad sobre la tierra.

¿Habrá palabras más lineales que éstas?

Sin embargo, no nos dejemos convencer sólo por estas líneas, pues deben señalarse dos detalles importantes que no están en ellas. Primero, estas últimas palabras de la novela se incluyen también en los pergaminos; y éstos existen en un presente eterno. Quizá nunca se repiten, pero tampoco dejan de existir. Por tanto, los Buendía no tendrán una segunda posibilidad de existencia porque ellos, al igual que los pergaminos, son eternos. Segundo, esta última sentencia no es la final en los pergaminos, sino la penúltima. Aureliano se ha detenido al leerla:

Antes de llegar al verso final ya había comprendido que no saldría jamás de ese cuarto, pues estaba previsto que la ciudad de los espejos (o los espejismos) sería arrasada por el viento y desterrada de la memoria de los hombres en el instante en que Aureliano acabara de descifrar los pergaminos (p. 351).

¿Termina Aureliano Babilonia de leer los pergaminos? Yo diría que no. Al igual que un mago todopoderoso interesado en salvar la novela y a los Buendía de la nada del olvido, García Márquez frena el tiempo

\footnotetext{
${ }^{27}$ Véase nota 2.
} 
y detiene el ciclo para siempre el momento antes de que se lea el verso final de los pergaminos. Metafóricamente, la novela resulta inacabable; la completamos nosotros, si es que la completamos (¿quién puede terminar de leer esta novela?) cada vez que la leemos. En efecto, el lector, al igual que Aureliano Babilonia, tiene que descifrar los pergaminos: y éstos son Cien años de soledad. Estamos con Aureliano Babilonia en el juego; existimos y nos vemos en «el espejo hablado». Es como si al ver Las Meninas de Velázquez, cuadro construido a base de la metáfora de los espejos, entráramos en un cuarto donde nos encontramos en el cuadro y reflejados en otro espejo. Mientras nos quedamos en el cuarto existimos en el espejo de Velázquez ${ }^{28}$.

Quedémonos en el Siglo de Oro por unos momentos. La autonomía creadora de García Márquez nos recuerda a Cervantes. En Don Quijote, Cervantes, con asombrosa autonomía, interrumpe la batalla entre Don Quijote y el Vizcaíno, dejándolos con las armas en alto mientras él discute otros asuntos. Regresa a la batalla y la termina sólo cuando él quiere y no antes (DQ, I, 8,9). Teóricamente, la digresión podría durar unos cien años. García Márquez se parece también a Cervantes en otras técnicas (y no es por casualidad, notémoslo de paso, que García Márquez era, o es todavía, aficionado de los libros de caballerías). Igual al Manco de Lepanto, quien tenía a Cide Hamete Benengeli, el colombiano tiene a Melquíades. A través de la traducción del árabe del libro de Cide Hamete Benengeli (Historia de Don Quijote de la Mancha, escrita por Cide Hamete Benengeli, historiador arábigo, en $D Q$, I, 9), Cervantes, sirviéndose de un «morisco aljamiado», que le traduce la historia, da al mundo con su héroe. Melquíades escribe los pergaminos que García Márquez ha titulado Cien años de soledad. Sin embargo, a diferencia de Cervantes, García Márquez ha designado a Melquíades como autor de los pergaminos y, a la vez, como personaje en ellos (¿o habría que indicar que el mismo Melquíades ha elegido este doble papel?, ¿o que García Márquez se ha puesto la misma máscara doble de autor y de gitano-personaje?). Y como Cervantes, quien utilizaba la técnica de la novela intercalada (por ejemplo, la novela del Curioso Impertinente),

${ }^{28}$ Así vi yo por primera vez Las Meninas en el Prado, pero, según tengo entendido, ya no está ese cuadro en el cuarto de espejos. Lástima; porque en ese cuarto y con ese cuadro vivimos la metáfora de Velázquez y también la que da estructura a Cien años de soledad; experimentamos además un topos renacentista muy común. Las Meninas es una obra muy discutida. Véase, por ejemplo, el primer capítulo de Michel Foucault, Les mots et les choses (Paris: Gallimard, 1966), y el artículo del filósofo americano John R. Searle «Las Meninas and the Paradoxes of Pictorial Representation», Critical Inquiry, 6, núm. 3 (1980), 477-488. 
que tiene sus equivalencias en otras literaturas europeas, García Márquez se sirve de la misma técnica. Pero a su modo. Es decir, su novela intercalada es la novela entera de Cien años de soledad, que existe dentro de - y es- la novela de Melquíades ${ }^{29}$.

El papel de Melquíades como personaje en la novela-pergaminos ( $E l$ Quijote de "cartapacios») es de suma importancia. Al igual que el señor Herbert en «El mar del tiempo perdido» y Pilar Ternera con los muchachos Buendía en el amor, Melquíades es un iniciador. A través de él los Buendía se enteran de los misterios de la magia, de la ciencia, de la alquimia y del sánscrito. Como todo iniciador en los misterios del mundo, Melquíades también conoce íntimamente a la muerte, pues ha «sucumbido a las fiebres en los médanos de Singapur, y su cuerpo [ha] sido arrojado en el lugar más profundo del mar de Java» (p. 22). Después de algún tiempo de muerto, regresa a Macondo (p. 39); y muerto por segunda vez, ésta en Macondo, regresa constantemente para enseñar los misterios a los varones de la familia. Los prepara poco a poco para la revelación final sobre su destino. Al iniciar a José Arcadio Buendía en la «ciencia» con el milagro de los imanes, Melquíades da el primer gran impulso a una aventura de búsqueda espiritual que culminará con el desciframiento de los pergaminos (y del destino de la familia) por Aureliano Babilonia.

E1 tema de la búsqueda espiritual se une desde luego con el del destino: al descubrir quiénes son los Buendía (en realidad, un Buendía solamente, pero éste - Aureliano Babilonia - representante de la familia entera) descifran o descubren su destino. El doble y simultáneo descubrimiento del destino y de la identidad trae a la memoria al Edipo, Rey de Sófocles. La figura principal de este drama descubre quién es (Edipo, hijo de Layo e hijo de su propia esposa), al mismo tiempo que se da cuenta que ha realizado su destino (el incesto), por más que haya luchado contra él (la profecía de la esfinge). Lo mismo les ocurre a los Buendía, aunque sólo el último Aureliano Babilonia entienda y experimente el carácter simultáneo de identidad y destino. Otro espejo hablado, pues; otro Aleph; otro Uroboros.

Concluyamos nuestro ensayo. Cien años de soledad termina en lo que Northrop Frye llama «el punto de la epifanía». Según Frye, en este punto «se encuentran alienados el mundo apocalíptico y el mundo cíclico» ${ }^{30}$. Este punto de epifanía - y el vocablo nos recuerda las teorías

${ }^{29}$ Carmen Arnau afirma que los pergaminos son la imagen de «la novela dentro de la novela»: El mundo mítico de Gabriel García Márquez (Barcelona: Ediciones Península, 1971), pág. 67.

${ }^{30}$ Frye, Anatomy of Criticism, p. 203. 
de James Joyce y la festividad que celebra la Iglesia católica el 6 de enero- es una imagen cósmica. Me parece que, como matriz operante en la obra de García Márquez, y en la tradición apocalíptica, se encuentra una visión tan rara y poderosa que se le puede ocurrir a un hombre - si es que se le ocurre- una vez en la vida. Aunque poderosa, la idea de esta visión es simple: el único momento en que se puede captar in toto a una persona, una ciudad o una civilización es el momento antes de morir; para una civilización, el último momento apocalíptico. En tales momentos, la visión es cósmica, estática, eterna, total; quizá mística y sí sumamente mítica. No puede dejar de serlo. Invoquemos, para terminar, las palabras de Platón, y describamos a Cien años de soledad como «una imagen moviente de la eternidad». 
